\title{
Erratum to: Sucrose regulated enhanced induction of anthraquinone, phenolics, flavonoids biosynthesis and activities of antioxidant enzymes in adventitious root suspension cultures of Morinda citrifolia (L.)
}

\author{
Md. Abdullahil Baque • Abdullah Elgirban • \\ Eun-Jung Lee $\cdot$ Kee-Yoeup Paek
}

Published online: 22 September 2011

(C) Franciszek Górski Institute of Plant Physiology, Polish Academy of Sciences, Kraków 2011

\section{Erratum to: Acta Physiol Plant}

DOI 10.1007/s11738-011-0837-2

In the original version of the paper, the units of anthraquinone, phenolics and flavonoids were expressed incorrectly in the abstract. The units should be in $\mathrm{mg} \mathrm{L}^{-1} \mathrm{DW}$ instead of $\mathrm{g} \mathrm{L}^{-1} \mathrm{DW}$.

The online version of the original article can be found under doi:10.1007/s11738-011-0837-2.

Md. A. Baque · E.-J. Lee · K.-Y. Paek ( $\square)$

Research Center for the Development of Advanced

Horticultural Technology, Chungbuk National University,

Cheongju 361-763, Republic of Korea

e-mail: paekky@chungbuk.ac.kr

Md. A. Baque

e-mail: bellah_77@yahoo.com

Md. A. Baque

Department of Agronomy, Sher-e-Bangla Agricultural

University, Sher-e-Bangla Nagar, Dhaka 1207, Bangladesh

A. Elgirban

Center of Excellence in Biotechnology Research, King Saud

University, Riyadh 11451, Kingdom of Saudi Arabia

E.-J. Lee

CBN PLANTECH Co. Ltd., Industry Academic Cooperation Foundation Agribusiness Incubator Center 206, Chungbuk

National University, Cheongju 361-763, Republic of Korea 